Dokuz Eylül Üniversitesi-Mühendislik Fakültesi

Fen ve Mühendislik Dergisi

Cilt 20, Sayı 59, Mayıs, 2018
Dokuz Eylul University-Faculty of Engineering Journal of Science and Engineering Volume 20, Issue 59, May, 2018

DOI: $10.21205 /$ deufmd. 2018205935

\title{
Kendiliğinden Yerleşen Beton Davranışının Hesaplamalı Akışkanlar Dinamiği İle Benzetimi
}

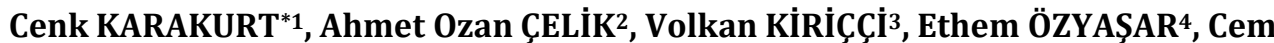 YILMAZER $^{5}$}

${ }^{1 B i l e c i k}$ Şeyh Edebali Üniversitesi, Mühendislik Fakültesi, İnşaat Mühendisliği Bölümü, 11210, Bilecik. (ORCID: 0000-0002-4204-5341)

${ }^{2}$ Anadolu Üniversitesi, Mühendislik Fakültesi, İnşaat Mühendisliği Bölümü, 26555, Eskișehir. (ORCID: 0000-0002-8770-2894)

${ }^{3}$ Anadolu Üniversitesi, Mühendislik Fakültesi, İnșaat Mühendisliği Bölümü, 26555, Eskişehir. (ORCID: 0000-0001-8856-2021)

${ }^{4}$ Bilecik Şeyh Edebali Üniversitesi, Mühendislik Fakültesi, İnşaat Mühendisliği Bölümü, 11210, Bilecik.

${ }^{5}$ Anadolu Üniversitesi, Mühendislik Fakültesi, İnşaat Mühendisliği Bölümü, 26555, Eskișehir. (ORCID: 0000-0001-8598-9468) Online Yayınlanma / Published Online: 15.05.2018)

Anahtar Kelimeler Kendiliğinden yerleșen beton, İşlenebilirlik, Bingham akışkanı, Parçacık taşınım modeli, Hesaplamalı akıșkanlar dinamiği

Kendiliğinden yerleşen beton (KYB) son nesil yüksek oranda su azaltıcı kimyasal katkıların beton teknolojisinde geliștirilmesiyle elde edilmiş olan özel beton tiplerinden birisidir. Bu çalıșmada farklı tasarım özelliklerine sahip taze KYB karışımlarının deneysel olarak elde edilen akış davranışının sayısal olarak modellenmesi amaçlanmıştır. Modellemede homojen akışkan kabulü yapılarak KYB'nin sayisal benzetimi V-hunisi, L-kutusu ve reometre deneylerinden elde edilen veriler yardımıyla Hesaplamalı Akışkanlar Dinamiği (HAD) ilkelerine göre yapılmıştır. Böylece elde edilen HAD yöntemi sayesinde standart laboratuvar deneylerinde önceden belirlenmesi mümkün olmayan ve KYB’nin uygulanacağı geometrinin boyut etkisine bağlı olarak değișen akıș davranıșını tespit etmek mümkün olabilecektir.

\section{Simulating the Behaviour of Self Compacting Concrete with Computitional Fluid Dynamics}

\section{Keywords}

Self compacting concrete,

Workability,

Bingham fluid, Particle tracking model,

Computational fluid dynamics

\begin{abstract}
Self-compacting concrete (SCC) is one of the latest generation special types of concrete that has been achieved through the development of concrete technologies to reduce water chemical additives. This work has aimed at numerically modeling the flow behavior of various design mixtures of fresh SCC features of which were obtained experimentally. Modeling was done for homogeneous fluid assumption of SCC in V-funnel, Lbox and using the data obtained from the rheometer test fluid dynamics. The validated Computational Fluid Dynamics (CFD) model obtained in this fashion will enable monitoring flow
\end{abstract}


behavior due to geometry, otherwise not possible to be detected through standard laboratory tests.

*Volkan KiRiççi: vkiricci@anadolu.edu.tr

\section{Giriş}

Kendiliğinden Yerleşen Beton (KYB), kendi ağırlığı ile döküldüğü kalıba yerleșebilen ve vibrasyon gerektirmeksizin kendiliğinden sıkışabilen özel bir beton türüdür. KYB'nin en önemli avantajı sık donatılı ve dar kesitli yapı elemanlarında, boșluksuz, ayrıșma ve terleme gibi problemler yaratmadan homojenliğini ve kohezyonunu koruyabilen, yüksek işlenebilirliğe sahip bir yapı malzemesi olmasıdır [1]. Geleneksel tasarıma sahip bir taze betonun kalıbina yerleştirilmesinde uygulanan vibrasyon, kullanılan ekipman ve hassas işçilik gibi inşaat hızını ve yapı maliyetini etkileyen ilave uygulamalara KYB'de genellikle gerek kalmaz [2]. Bunun sonucunda enerji tüketimi, işçilik maliyetleri ve porozitesi düşük, yüksek dayanıklılığa sahip sağlıklı beton ve betonarme yapı elemanlarının üretimi kolaylıkla yapılabilmektedir. $\mathrm{Bu}$ özelliklerinden dolayı son ylllarda KYB uygulamalarına olan ilgi artmış ve fiziksel modele dayalı pek çok çalışma literatürde rapor edilmiștir [1, 3-4].

Özellikle sı donatılı betonarme elemanlarda agregalar birbirine dayanarak "kemerlenme" oluşturabilmektedir. Böyle bir kemerlenme mekanizmasının bulunduğu betonun bir delikten aktığ iki boyutlu bir modeli Şekil 1'de görülmektedir [5].

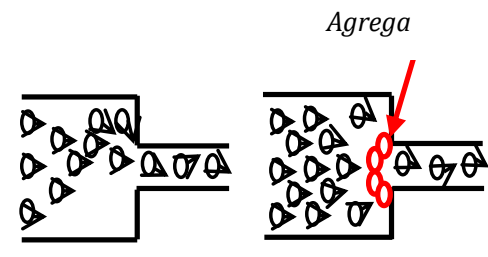

Şekil 1. Agrega kemerlenmesi [5]
KYB'nin ayrışma göstermeksizin dar ve sık donatılı kesitlerden geçebilme özelliklerinin belirlendiği standartlarca kabul edilmiş birçok deney yöntemi bulunmaktadır [6]. Ancak özellikle büyük ölçekli, donatılı ve karmaşık geometrilere sahip inşaat elemanlarındaki KYB uygulamalarında karşılașılacak riskleri laboratuvar deneyleri ile önceden tespit edebilmek bazen oldukça zordur.

Sayısal çözümleme yöntemlerinin gelişmesi ve hesaplama kapasitesinin artmasıyla birlikte mühendislik problemlerinin sayısal benzetim tekniklerine dayalı çözümü hızla yaygınlașmaktadır. Özellikle analitik çözümün mümkün olmadığı karmaşık akışkanlar dinamiği problemlerinin bilgisayar ortamında sayısal benzetiminin yapıldığı Hesaplamalı Akışkanlar Dinamiği (HAD) önemli bir disiplin olarak gelişmektedir. KYB'nin sayısal benzetimi üzerine son yıllarda birçok çalışma yapılmıştır. Literatürde rapor edilen KYB'nin akışkan davranışının bilgisayar ortamında sayısal benzetiminin yapıldığı sayısal model uygulamaları homojen akışkan varsayımına dayanmakta ve agrega etkileri ihmal edilmektedir [7-9].

Temel olarak Newtonyen olmayan akıșkan akıșı Bingham tipi model ile açılkanmaktadır. Bu yöntemle Deeb vd., lifsiz KYB akışı sırasında Lagrange yaklaşımı temeline dayanan, sayısal ağ gerektirmeyen bir nümerik yöntem olan yumuşatılmış parçacık hidrodinamiği (Smoothed Particle Hydrodynamics) metodunu kullanarak üç boyutlu benzetim oluşturmuş ve büyük agregaların ( $8 \mathrm{~mm}$ ve daha büyük) dağılımı üzerine odaklanmışlardır [10]. 
Laboratuvarda yapılan L kutusu testi ile benzetim sonuçları karşılaştırılarak bu yöntemin yetenekleri çoğu zaman doğrulanabilir. Georgiadis vd. ise KYB laboratuvar testleri için sürekli bir benzetim yaklaşımı kullanmıștır [9]. Daha ayrıntılı olarak, yaygın olarak kullanılan "L- kutusu" ve "V- hunisi" testleri HAD teknikleri kullanılarak simüle edilmiştir. Beton, Newtonyen olmayan akışkan olarak homojen bir madde olarak modellenmiştir. Böylece agrega etkileri bir Bingham (Plastik viskozite) modele uyarlanarak, engelleme ve ayrışma ihmal edilmiştir. Bu tür bir yaklaşımın eksiklikleri olduğu gibi beraberinde getirdiği avantajlarda bulunmaktadır. Özellikle KYB kalıp doldurma özelliklerini doğrudan fiziksel olarak doğrulanabilecek viskozite parametresine bağlı olarak oldukça yaklaşı bir biçimde tespit edilebilmesine imkân sağlamaktadır. Viskoplastik sonlu elemanlar metodu ve viskoplastik bölünmüş sonlu elemanlar metodu kullanılarak gerçekleştirilen benzetimlerde taze beton davranışının belirli reolojik özellikler altında homojen bir akışkan gibi modellenerek doğru sonuçlar ortaya koyduğu görülmüștür [11,12]. Diğer taraftan ayrıklaştırılmış parçacık modellerine göre çok daha büyük geometrilerin ve çözüm alanlarının daha az hesaplama gücü ile benzetiminin yapılabilmesini sağlamaktadır.

Farklı ölçeklerdeki problemleri modellemek için yararlı üç farklı uygulama sunulmuştur: i) parçacıklar, betonda her biri bir agregayı temsil eder, ii) akışkan, betonu homojen bir akışkan olarak modelleme ve iii) akışkan parçacığı, akış ayrıntılarını incelemek. Sayisal benzetim ile istatistiksel yöntemleri karşılaştırarak değerlendirme yapan çalışmalar da mevcuttur [13]. Beton akışının benzetimi hem ayrık hem de sürekli yöntemler kullanılarak incelenebilir.
Burada agregalar ile ilgili davranışlar ayrı ayrı parçacıkları benzetmek için bir araç olarak sunulur ve ayrı nesneler olarak modellenir. Genelde benzetimlerde küresel parçacıklar, agregayı temsil etmek için kullanılır. Bununla birlikte, küresel olmayan parçacıklardan yararlanmak da mümkündür. Agrega yüzey pürüzlülügü, boyutu ve boy oranı istenen parçacık şekli, parçacık halinde sürtünme, boyut ve topaklanma oluşturan birkaç küre ile model olabilmektedir. Betonu simüle etmek için ise sürekli bir yaklaşım kullanılmaktadır. Beton homojen bir malzeme gibi modellenip, agrega özel etkileri, engelleme ve ayrışma olarak açılkanamaz. Fakat Bingham modeli ile simüle edilen beton laboratuvar testleri (örneğin; çökme-yayılma, L-kutusu) kullanılarak iyi bir benzerlik elde edilebilir. Akış özelliğinin bir bölümü sıkışık çift levha beton olan çok katmanlı tam ölçekli duvar başarıyla simüle edilmiştir [14].

Bu çalışmada öncelikle homojen akışkan kabulü ve agrega etkileri ihmal edilerek KYB'nin sayısal benzetimi yapılmıștır. Sayısal benzetim sonuçları laboratuvarda gerçekleştirilen V-hunisi, L-kutusu ve reometre deney sonuçları ile karşılaştırılarak HAD analizinin doğruluğu ve hassasiyeti test edilmiştir.

\section{Malzeme ve Yöntem}

\subsection{Malzemeler}

Çalışmada KYB üretimi için Bilecik SANÇİM çimento fabrikası ürünü olan CEM I 42,5 R tipi Portland çimentosu kullanılmıştır. KYB'nin taze haldeki akış davranışında ayrışmanın engellenmesi için karışımda kullanılan ince malzeme miktarı çok iyi ayarlanmalıdır. Bu amaçla karışımda mineral katkı olarak Kütahya Tunçbilek Termik Santralinden temin edilen $F$ tipi uçucu kül kullanılmıștır. Çalışmada KYB karışımlarında kullanılan çimento ve 
uçucu külün özellikleri aşağıda Tablo 1 de sunulmuştur.

Tablo 1. Çimento ve uçucu külün özellikleri.

\begin{tabular}{|c|c|c|c|c|}
\hline Bileşen & $\begin{array}{c}\text { CEM I } \\
42.5 \mathrm{R} \\
(\%)\end{array}$ & $\begin{array}{c}\text { Uçucu } \\
\text { Kül } \\
(\%)\end{array}$ & \multirow{3}{*}{\multicolumn{2}{|c|}{$\begin{array}{c}\text { CEM I } 42.5 \mathrm{R} \\
\text { Fiziksel ve Mekanik Özellikler }\end{array}$}} \\
\hline $\mathrm{SiO}_{2}$ & 20.54 & 59.06 & & \\
\hline $\mathrm{Al}_{2} \mathrm{O}_{3}$ & 5.52 & 17.27 & & \\
\hline $\mathrm{Fe}_{2} \mathrm{O}_{3}$ & 3.71 & 12.44 & İncelik, $\left(\mathrm{cm}^{2} / \mathrm{g}\right)$ & 3445 \\
\hline $\mathrm{CaO}$ & 63.87 & 1.68 & Özgül Ağırlık & 3.15 \\
\hline $\mathrm{MgO}$ & 1.50 & 4.54 & Piriz Başlama, (saat:dakika) & $3: 00$ \\
\hline $\mathrm{K}_{2} \mathrm{O}$ & 0.56 & 1.15 & Piriz Sonu, (saat:dakika) & $4: 00$ \\
\hline $\mathrm{Na}_{2} \mathrm{O}$ & 0.33 & 0.30 & Le Chatelier Genleşmesi, (mm) & 3 \\
\hline $\mathrm{SO}_{3}$ & 2.84 & 0.60 & Basınç Dayanımı 2 gün, (MPa) & 25.45 \\
\hline $\mathrm{Cl}$ & 0.008 & 0.002 & Basınç Dayanımı 7 gün, (MPa) & 38.30 \\
\hline Kizdırma K. & 1.15 & 2.31 & Basınç Dayanımı 28 gün, (MPa) & 49.10 \\
\hline
\end{tabular}

KYB’nin akış davranışında ve karışımın homojenliğini korumasında kullanılan agrega miktarı ve tane dağılımı çok önemlidir. KYB karışımlarında agrega olarak Eskişehir Seryapı Prefabrik Fabrikasından temin edilen kalker kökenli ince ve iri kırmataș agrega $0-4 \mathrm{~mm}$ ve $4-12 \mathrm{~mm}$ boyutlarında kullanılmıștır (Tablo 2).

Tablo 2. Agreganın fiziksel özellikleri.

\begin{tabular}{ccc}
\hline Özellik & $\begin{array}{c}\text { İnce } \\
\text { Agrega } \\
(0-4)\end{array}$ & $\begin{array}{c}\text { İri } \\
\text { Agrega } \\
(4-12)\end{array}$ \\
\hline $\begin{array}{c}\text { Suya Doygun Yoğunluk } \\
\left(\mathrm{kg} / \mathrm{dm}^{3}\right)\end{array}$ & 2.70 & 2.70 \\
$\begin{array}{c}\text { Gevșek Birim Ağrılık } \\
\left(\mathrm{kg} / \mathrm{dm}^{3}\right)\end{array}$ & 1.45 & 1.62 \\
$\begin{array}{c}\text { Sıkı Birim Ağılık } \\
\left(\mathrm{kg} / \mathrm{dm}^{3}\right)\end{array}$ & 1.59 & 1.74 \\
$\begin{array}{c}\text { Su Emme Oranı } \\
(\%)\end{array}$ & 2.06 & 0.41 \\
\hline
\end{tabular}

Yapılan çalışmada yüksek performanslı akışkanlaștırıcı beton katkısı olarak özellikleri Tablo 3'te verilen BASF Glenium C 303 marka yeni nesil hiper akışkanlaştırıcı kimyasal beton katkısı kullanılmıştır. Karışımlarda kullanılan malzemelerin genel görüntüsü Şekil 2'de görülmektedir. Karışımlarda katkı oranı deneme üretimleri ile belirlenerek karışım suyunun yarısı ile karıştırılarak kullanılmıştır.

Tablo3. Kimyasal katkı özellikleri.

\begin{tabular}{ll} 
Özellik & BASF Glenium C 303 \\
\hline Kimyasal Yapısı & Polikarboksilik Eter \\
Renk & Açık Yeşil \\
Yoğunluk, kg/dm ${ }^{3}$ & $1,023-1,063$ \\
Klor İçeriği, (\%) & $<0,1$ \\
Alkali İçeriği, (\%) & $<3$ \\
\hline
\end{tabular}

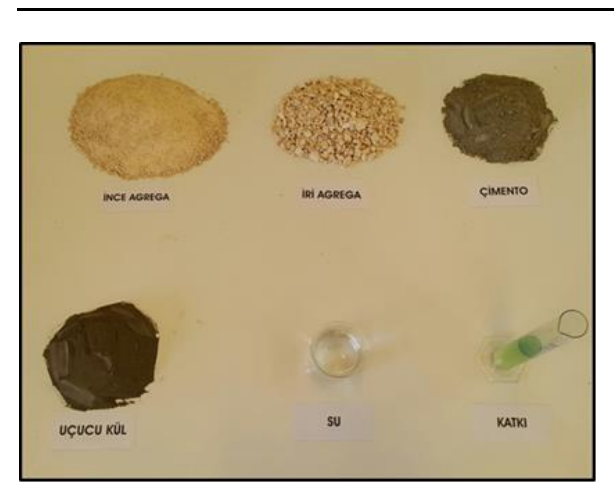

Şekil 2. KYB karışım malzemeleri

\subsection{KYB Tasarımı}

Çalışmada öncelikle kullanılan malzemelerin fiziksel özellikleri belirlenerek beton tasarımının 
yapılması için gerekli veriler elde edilmiştir. Agregaların tane dağılımı elek analizi deneyi ile belirlenmiștir [15]. Bu özelliklerin belirlenmesinden sonra KYB tasarımına geçilerek farklı karışım oranlarında ve tane boyutlarında KYB tasarımları European Federation of National Associations Representing for Concrete (EFNARC) yöntemine göre tasarlanmıştır [6]. Tasarlanan KYB karışımları Tablo 4'de görülmektedir. KYB tasarımında iki farklı bağlayıcı oranı kullanılmıştır. Burada çimento ve kül miktarı sırasıyla $420 \mathrm{~kg} / \mathrm{m}^{3}$ ve $550 \mathrm{~kg} / \mathrm{m}^{3}$ olacak şekilde tasarım yapılmıştır. Toplam agrega hacmi içerisindeki agrega kullanım oranları ise ince/iri oranı 0.42 ile 0.67 olacak şekilde karışımlar hazırlanarak farklı agrega gradasyonu içeren karışımlar elde edilmeye çalışılmıştır. Böylece farklı akış davranışları elde edilerek sayısal modelleme için gerekli olan davranışların karşılaștırılması yapılabilmiştir. Tasarımlar yapılırken birçok deneme karışımı yapılmış olup uygun görülen 6 karışım üzerinde deneyler yürütülmüştür. Karışım tasarımlarında veri zenginliği için farklı kıvamlara sahip KYB üretimleri gerçekleştirilerek farklı yerleşme davranışına sahip betonların elde edilmesi amaçlanmıştır.

Tablo 4. KYB karıșım tasarımı ( $\left.1 \mathrm{~m}^{3}\right)$.

\begin{tabular}{ccccccc}
\hline Kod & $\begin{array}{c}\text { Çimento } \\
(\mathrm{kg})\end{array}$ & $\begin{array}{c}\text { Uçucu Kül } \\
(\mathrm{kg})\end{array}$ & $\begin{array}{c}\text { İri Agrega } \\
(\mathrm{kg})\end{array}$ & $\begin{array}{c}\text { İnce Agrega } \\
(\mathrm{kg})\end{array}$ & $\begin{array}{c}\text { Su } \\
(\mathrm{kg})\end{array}$ & $\begin{array}{c}\text { Katkı } \\
(\mathrm{kg})\end{array}$ \\
\hline K1 & 310 & 110 & 510 & 1240 & 197 & 13 \\
K2 & 310 & 110 & 700 & 1050 & 202 & 11 \\
K3 & 350 & 200 & 470 & 1097 & 160 & 8 \\
K4 & 400 & 150 & 525 & 1225 & 221 & 11 \\
K5 & 350 & 200 & 470 & 1097 & 220 & 11 \\
K6 & 350 & 200 & 470 & 1097 & 247 & 11 \\
\hline
\end{tabular}

\subsection{Karakterizasyon Teknikleri}

KYB numunelerinin işlenebilirlikleri en yaygın kullanılan ve uygulaması kolay olan V-hunisi [16], L-kutusu [17] ve Schleibinger BT-2 taze beton reometresi kullanılarak belirlenmiștir. Deneyler sırasında beton akışının Vhunisi ve L-kutusu kesitinden izlenerek görüntü alınabilmesi için pleksiglas malzemeden şeffaf özel deney düzenekleri üretilmiştir. İşlenebilirlik deneyleri sırasında taze betonun akış davranışı modelleme aşamasında kullanmak için Panasonic Lumix DMC- GH4 marka ağır çekim (96 fps) kamerası ile eşzamanlı olarak kayıt altına alınmıştır (Şekil 2). Ayrıca beton akışı sırasında beton kütlesindeki zamana bağlı değişimin belirlenmesi için V-hunisinin alt tablasına dijital hassas terazi yerleştirilmiștir. Böylece ağır çekim kamerasında zamana bağlı beton kütlesindeki değişiklikler kayıt altına alınmıştır. Elde edile taze beton deney sonuçları ANSYS CFX yazılımı kullanılarak modellenmiştir.

\subsection{Yöntem}

Analizlerde iki aşamalı bir çalışma programı yürütülmüştür. İlk aşamada farklı tane dağılımı ve içeriğe sahip olan KYB karıșımları hazırlanmış ve bu karışımlar üzerinde V-hunisi, L-kutusu ve taze beton reometresi deneyleri yapılmıştır [16, 17]. Böylece taze KYB'nin işlenebilirlik davranışı deneysel olarak belirlenmiştir. Vhunisi ve L-kutusu deneyleri yapılırken ayrıca taze betonun akış davranışı yavaş çekim kamerası ile eşzamanlı olarak kayıt altına alınarak buradan elde edilen akış davranışları HAD benzetiminde kullanılmıştır. İkinci çalışma aşamasında homojen akışkan kabulü yapılarak KYB'nin HAD 
modeli oluşturulması amaçlanmıştır. HAD uygulamalarında bir mühendislik probleminin çözümü Önişleme (Preprocessing), Çözücü (Solver) ve Son işleme aşamalarından (Post-Processing) Önişleme aşamasında problemin geometrisi tanımlanır, hesaplama ağı olușturulur, akışkana ait fiziksel özellikler belirlenir, probleme ait başlangıç ve sınır koşulları tanımlanır. Burada ilk aşamada gerçekleştirilen deneylerin üç boyutlu geometrileri ANSYS CFX yazılımının bir modülü olan DesignModeler kullanılarak tanımlanmış ve geometriye uygun hesaplama ağı yine ANSYS CFX bünyesindeki mesh (grid) modülü ile oluşturulmuştur. Akışkan modeli için $\frac{\partial \bar{u}_{i}}{\partial x}=\mathbf{0}$

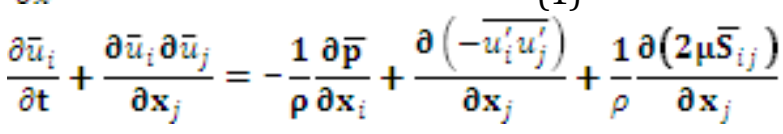

$\left(\bar{s}_{i j}=\frac{\left[\frac{\partial \bar{u}_{i j}}{\partial \mathrm{x}_{j}}+\frac{\partial \overline{\bar{p}_{j}}}{\partial \mathrm{x}_{i j}}\right]}{2} ;\right.$ deformasyon hızı tensorü)

Burada Eş.1, en genel tensor hali ile süreklilik (kütlenin korunumu) denklemidir. Eș.2 ile genelleştirilen denklemler ise, 3 doğrultuda (i: $\mathrm{x}, \mathrm{y}, \mathrm{z}$ ) momentumun korunumu denklemleridir. Burada üst çizgi Reynolds ortalamasını (zamansal ortalama) işaret etmektedir.

Elbette buradaki gibi bir Newtonyen olmayan KYB benzetiminde akım, doğrusal bir kayma gerilmesi ve kayma oranı ilişkisi ile açıklanamayabilir. Bingham modelinde tanımlandığ şekilde ek olarak sabit bir (akma) gerilmesinin dâhil edilmesi ve bu şekilde viscoplastik davranışın yansıtılması gerekmektedir [8-10]. Yani deformasyonun başladığı kayma gerilmesi değeri süreklilik ve momentum denklemlerine ek olarak
ANSYS CFX yazilıminda tanımlı Newtonyen olmayan akışkan modelleri kullanılarak KYB için en uygun akışkan modeli belirlenmeye çalışılmıştır. HAD çalışmasında geometri oluşturulması ve sayısal ağın inşasından sonra çözücü (Solver) aşaması takip edilmiştir. Bu aşamada hesaplamanın yapılacak ortam ayarları, hesaplamada kullanılacak bilgisayar hassasiyeti (single ya da double precision) olarak belirlenmekte, hesaplayıcı kaynağının büyüklüğüne göre hesaplama süresi ortaya çıkmaktadır. Çözüm için model aşağıdaki Reynolds ortalamalı NavierStokes (RONS) denklemleri olarak isimlendirilen akıma ait denklem takımını çözmektedir: modellemede kullanılmaktadır. Yukarıda verilen RONS denklemlerinin (Eş.2) analitik ve gerçek çözümü günümüze kadar yapılamamıştır. Bu nedenle denklem sisteminin çözümü için sonlu farklar, sonlu elemanlar ya da sonlu hacimler gibi sayısal yaklaşık yöntemler kullanılmaktadır. Sonlu elemanlar tabanlı yöntemler lineer olmayan kısmi türevli diferansiyel denklemleri, günümüz hesaplayıcılarının hesaplayabileceği forma yani cebrik denklem haline indirgemektedir. İndirgeme aşamasında hesaplama hassasiyetinin düşmemesi için zamanda ve uzayda ikinci mertebeden yakınsak sayısal yöntemler tercih edilmiştir.

Özellikle serbest yüzey ve türbülans büyüklüklerinin ikinci mertebeden yakınsak çözümlerinin elde edilmesi için hesaplama ağının mümkün 
olduğunca sık seçilmesi gerekmekte, bu da hesaplama süresini arttırmaktadır. Bu çalıșmada KYB akımı laminar akım olarak modellenmiştir. HAD analizinin son aşamasında ise (post-processing) hesaplama sonuçları grafik, tablo ya da animasyon olarak hazırlanmakta, hesaplama bölgesi içindeki fiziksel büyüklüklerin değişimi görselleştirilmektedir.

Gerçekleştirilen çözüm doğası itibariyle nümerik bir yaklaşım içerdiği için gerçek çözümle arasında kaçınılmaz hata payları barındırmaktadır. Bu nedenle doğru ve yakınsak bir çözüm elde edebilmek için, tipik bir HAD analizine ait daha öncesinde bahsi geçen tüm aşamaların (geometri, sayısal ağ, başlangıç ve sınır koşulları) her bir adımında tüm detaylar dikkatlice irdelenmiștir. Bu tür özellikli akış problemlerin çözümünde zamanda ve uzayda yakınsak çözümler edebilmek için hesaplama ağını ve sınır koşullarını çok dikkatli bir şekilde tanımlanmalıdır. HAD analizleri sonucu elde edilen sayısal sonuçlar deney sonuçları ile karşılaştırılarak akışkan modelinin ve sayısal çözümün doğruluğu ve hassasiyeti belirlenmiştir.

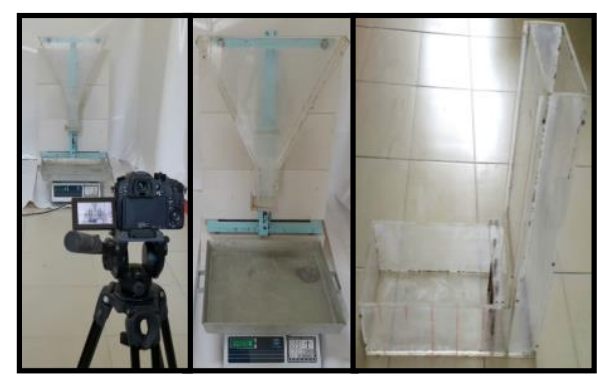

Sekil 2. Seffaf V-hunisi ve L-kutusu deney düzenekleri

\section{Bulgular}

\subsection{Elek Analizi Deneyi}

KYB karışımlarında kullanılacak olan agreganın tane dağılımı elek analizi deneyi ile belirlenmiştir. Agrega numuneleri $105^{\circ} \mathrm{C}$ sicaklıkta 24 saat süreyle etüvde kurutularak tamamen kuru hale getirilmiştir. Sonrasında kuru hale getirilmiş olan agrega numuneleri elek sarsma cihazı kullanılarak elenmiştir. KYB'nin iyi bir akış, yayılma ve geçiş yeteneğine sahip olabilmesi için KYB karıșımında kullanılacak olan en büyük agrega tane çapının $16 \mathrm{~mm}$ veya daha az olması tercih edilmektedir [4, 19]. Deneysel karıșımlarda kullanılan en büyük agrega tane çapı $12 \mathrm{~mm}$ olacak şekilde belirlenmiş ve KYB tasarımları buna göre yapılmıştır. Agregalar üzerinde yapılan elek analizi sonucunda elde edilen granülometri eğrisi Șekil 3'de görülmektedir.

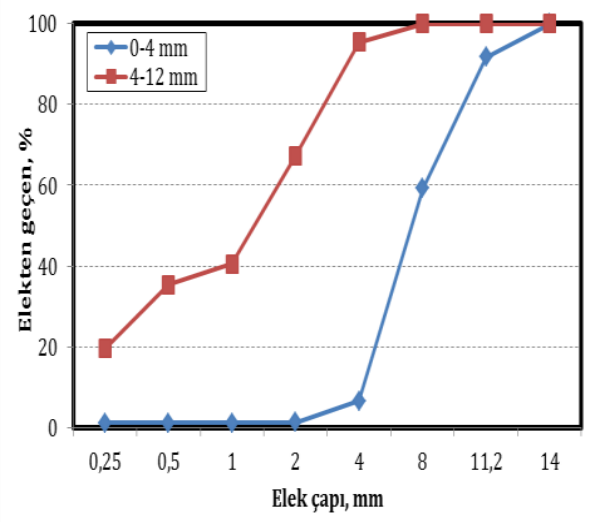

Şekil 3. Agrega granülometri eğrisi

\section{2. İşlenebilirlik Deneyleri}

Taze KYB karıșımlarında V-hunisi deneyi ile betonun akış özelliği ve Lkutusu deneyi ile de KYB'nin geçiş özellikleri belirlenmiştir. Deney sırasında zamana bağlı akıș davranışı ağır çekim kamera ile belirlenmiştir. $\mathrm{Bu}$ amaçla L-kutusu üzerinde $100 \mathrm{~mm}$ arayla referans çizgileri çizilmiştir [20]. Deney düzeneklerinden elde edilen V-hunisi ve L-kutusu deneyi beton akış görüntüleri Şekil 4 ve 5 'te görülmektedir. 


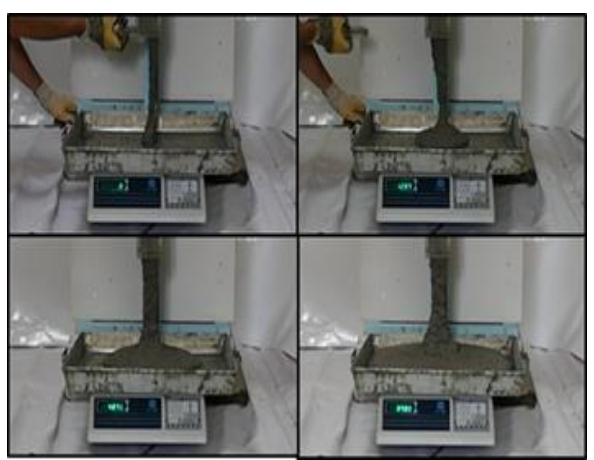

Şekil 4. V- hunisi deneyi KYB akışı

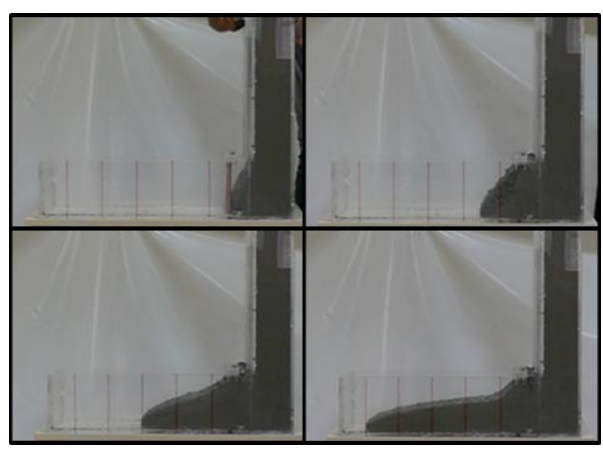

Şekil 5. L-kutusu deneyi KYB akışı

Elde edilen gerçek akıș görüntüleri ile HAD modelinden elde edilen görüntüler birbiriyle karşılaştırılarak modelin gerçek akışkan davranışını gösterip göstermediği test edilmiştir. V-hunisi ve L kutusu deneylerinden elde edilen geçiş süresi ve geçiş kabiliyeti oranları Tablo 5'de verilmiştir. V-hunisi deney sonuçları incelendiğinde KYB karışımlarının huniden akış sürelerinin 6 sn ile 120 sn arasında değiştiği görülmüştür. EFNARC [6] KYB tasarımında V-Hunisi geçiş süresi VS1/VF1 sınıfı için $\leq 8$ sn ve VS2/VF2 sınıfı için 9-25 sn arasında olması gerekmektedir. $\mathrm{Bu}$ sonuçlar Tablo 1'de verilen karışım oranlarıyla birlikte değerlendirildiğinde toplam bağlayıcı miktarı $550 \mathrm{~kg} / \mathrm{m}^{3}$ (çimento + uçucu kül) olan KYB karışımlarının en uygun akış değerlerinin elde edildiği görülmüştür.

En düşük akış sürelerinin elde edildiği K4, K5 ve K6 numunelerinde su/bağlayıcı oranı 0.40-0.45 arasında
Tablo 5. KYB Karışımlarının işlenebilirlik değerleri.

\begin{tabular}{ccccc}
\hline Kod & $\begin{array}{c}\mathrm{V} \\
\text { Hunisi } \\
(\mathrm{sn})\end{array}$ & $\begin{array}{c}\text { Geçiş } \\
\text { (PL) }\end{array}$ & $\begin{array}{c}\text { Viskozite } \\
\text { (Nmms) }\end{array}$ & $\begin{array}{c}\text { Akma } \\
\text { Direnci } \\
\text { (Nmm) }\end{array}$ \\
\hline K1 & 20 & 0.93 & 11650 & 271 \\
K2 & 73 & 0.75 & 6060 & 280 \\
K3 & 120 & 0.64 & 31226 & 88 \\
K4 & 11 & 0.92 & 3766 & 111 \\
K5 & 10 & 0.98 & 7743 & 34 \\
K6 & 6 & 0.99 & 2522 & 249 \\
\hline
\end{tabular}

değişmiştir. L-kutusu deney sonuçları incelendiğinde KYB'nin geçiș kabiliyeti değerlerinin 0.99 ile 0.82 arasında değiștiği görülmektedir. Genel olarak bu değerin geçiş yeteneği açısından 0.80 üzerinde olması gerekmektedir [1]. KYB tasarımlarında kullanılan farklı malzeme oranları ile akış sürelerinin ve geçiş kabiliyeti değerlerinin değişkenlik göstermesi ile HAD modelinde farklı veri beslemesi sağlanabilmiştir.

Çalışmada taze beton için Alman malı Schleibinger BT-2 model reometre kullanılmıștır. Bu deney düzeneği ile farklı tasarım özelliklerine sahip KYB karışımlarının viskozite ve kayma dirençleri belirlenmiştir. Reometreden elde edilen sonuçlar Tablo 2'de görülmektedir. Buradan elde edilen grafiklerdeki değerler hız (m/s) ve Tork (Nmm) değerleri yer almaktadır. Reometre deney sonuçlarından elde edilen grafiklerde, doğrunun " $y$ " eksenini kestiği nokta "bağll kayma eşiği" değerini, doğrunun eğimi ise "bağll viskoziteyi" vermektedir.

Deney sonuçlarına göre, bağıl viskozite değerlerinde en büyük değeri 31226 ile K3 karışımı almıştır. Bu sonuçta su/bağlayıcı oranının 0.29 olarak seçilmesi ve akışkanlaştırıcı katkı oranının diğer karışımlara göre daha düşük olması rol oynamıştır. En düşük viskozite değerini ise 2522 değeri ile K6 karışımı almıştır. K6 karışımında 
su/bağlayıcı oranının 0.45 olarak seçilmesi ile birlikte karışımda kullanılan kimyasal katkı miktarının bu sonucun elde edilmesinde etkili olmuştur. Reometre sonuçlarının Vhunisi akış süresi ve L-kutusu geçiş kabiliyeti sonuçlariyla uyumlu oldukları Tablo 2'den görülmektedir.

\subsection{KYB Davranışı Modellemesi}

TS EN 12350'de belirtilen standartlara ve ölçülere bağlı kalarak oluşturulmuş $\mathrm{V}$ hunisi ve $\mathrm{L}$ kutusu deney sistemlerinin üç boyutta bire bir ölçekli bilgisayar destekli çizim modelleri hazırlanmıştır. Hazırlanan geometri, sonlu küçük hacimlere ayrıklaştırılarak sayısal çözüm ağı (mesh) oluşturulmuştur. Kullanılan sayısal ağ, $\mathrm{V}$ hunisi için yaklaşık 1,5 milyon, L kutusu için yaklaşı 2,5 milyon ağ elemanı içermektedir. A $\breve{g}$ elemanları, geometrik anlamda yüksek oranda dar açllı köşelere sahip elemanlar (skewness) içermeyecek biçimde iyileştirilmiştir. Söz konusu sayısal ağ, daha gerçekçi ve hassas bir sonuç elde edebilmek için gerekli bölgelerde sıklaştırma uygulanmış ve uygun eleman boyutları kullanılarak oluşturulmuştur (Şekil 6).
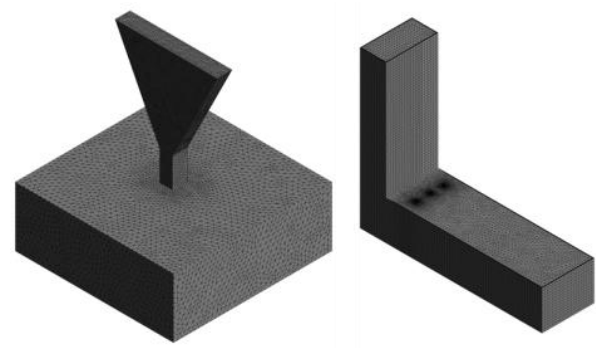

Şekil 6. Deneyler için oluşturulan sayısal ağ

Model kurulduktan sonra gerekli olan sınır koşulları, malzeme özellikleri ve çözüm metodu ile ilgili özelliklerin belirlenerek probleme özgü koşullar modele yansitılmıştır. Tüm geometrinin oluşturulması, sayısal ağın oluşturulması ve benzetimin gerçekleştirilmesi aşamalarında ANSYS CFX yazılımı kullanılmıştır. Analizler sonlu hacimler yaklaşımı altında, hareketsiz sayısal ağ elemanları kullanılarak akıșkanların hacmi modeli (VOF) ile gerçekleștirilmiştir. KYB akım davranışı, Newtonyen olmayan akışkanlar için kullanılan iki parametreli Bingham Plastik reoloji modeli ile tanımlanmıştır. Gerekli malzeme ve reolojik özellikler (akma gerilmesi ve plastik viskozite) deneysel olarak belirlenen ve KYB limitleri bakımından en uygun koşulları verenlerden $\mathrm{K} 1, \mathrm{~K} 4$ ve $\mathrm{K} 6$ karışımındaki değerler olarak tercih edilmiştir [6]. Benzetim başlangı̨̧ koşulu olarak " $\mathrm{t}=0 \mathrm{sn}$ " anında $\mathrm{V}$ hunisi için huni kısmı, L kutusu için dikey kutu kısmı TS EN 12350 standardında da belirtildiği gibi KYB özellikleri taşıyan akışkan ile doldurularak deneyler benzer koşullarda sayısal olarak oluşturulmuştur. HAD sayısal benzetim sonuçları incelendiğinde, $\mathrm{V}$ hunisi ve L kutusu için akış ve geçiş değerlerinin deneysel sonuçlarla birebir örtüşmemekle birlikte uyum içerisinde olduğu gözlemlenmiştir (Şekil 7-8).

Şekil 7, 8 ve Tablo 6 üzerinde K1, K4 ve K6 karıșımları için gerçekleștirilen HAD benzetim sonuçları karşılaştırmalı olarak gösterilmektedir. Deneysel olarak K1 karışımının $\mathrm{V}$ hunisi deneyinde aldığı geçiş süresi 20 sn iken bu değer HAD benzetiminde 20.2 sn olarak tespit edilmiştir. K4 karışımında, $\mathrm{V}$ hunisi geçiş süreleri deneysel ve HAD benzetimleri için sırasıyla 11 sn ve 10.6 sn olarak ölçümlenmiștir. K6 karıșımda ise söz konusu değerler arasındaki farkın diğerlerine oranla daha fazla olduğu görülmüştür. K6 için deneyden elde edilen $\mathrm{V}$ hunisi geçiş değeri 6 sn iken HAD analizinde bu süre 7.1 sn olarak ölçümlenmiştir. Şekil 7 üzerinde de görülebileceği gibi viskozite ve kayma gerilmesi görece yüksek olan K1 
karışımının akım davranışının diğer iki karışıma göre farklı olduğu görülebilmektedir. K4 ve K6 karışımları incelendiğinde ise $\mathrm{K} 4$ karıșımının akma direnci K6 karışımına göre daha düşük olmasına rağmen viskozitesi yüksek olduğu için K6 karıșımından daha uzun sürede $\mathrm{V}$ hunisinden geçiş yapmaktadır.

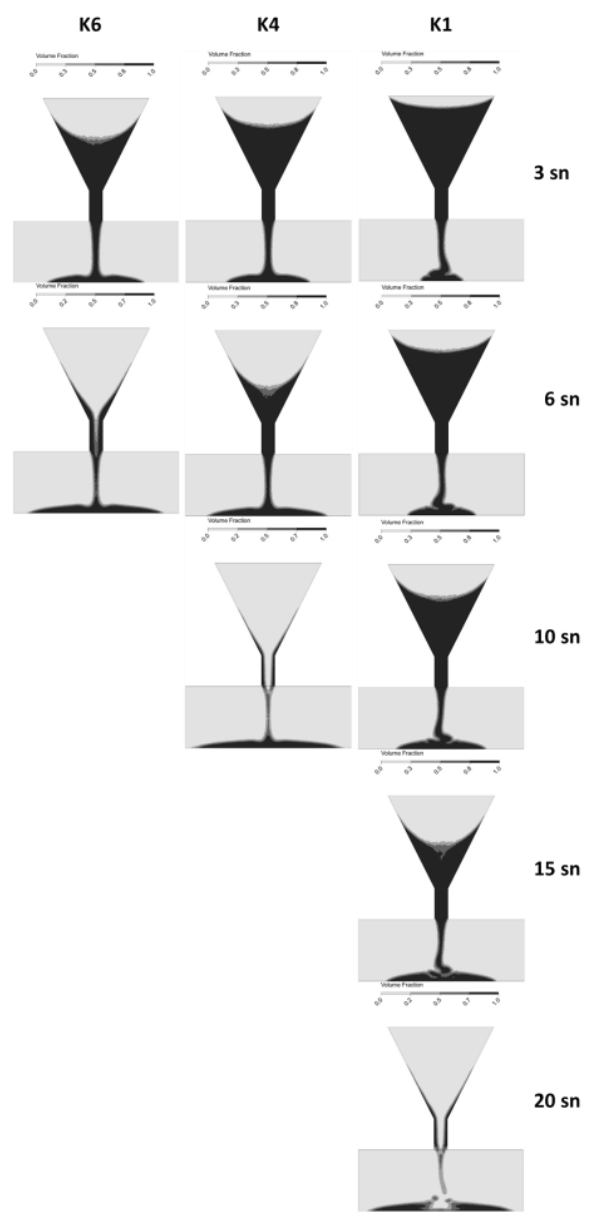

Şekil 7. K1, K4 ve K6 karışımları için V hunisi HAD benzetim sonuçları

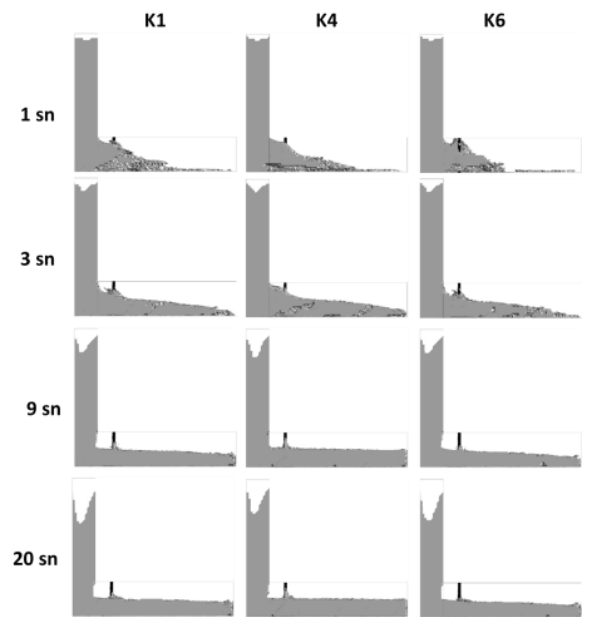

Şekil 8. K1, K4 ve K6 karışımları için L kutusu HAD benzetim sonuçları

L kutusu benzetimlerinde de benzer biçimde deneysel geçiş değerleri ile uyum sağlanmaktadır. Sırasıyla K1, K4 ve K6 karışımları için HAD benzetim geçiş değerleri 0.88, 0.94 ve 0.96 olarak ölçümlenmiştir. Burada deneysel sonuç ile arasında en büyük fark olan karıșımın K1 olduğu görülmekle birlikte L kutusu geçiş değeri ölçümlerindeki hassasiyet açısından yeterli seviyede uyumlu oldukları ifade edilebilir.

Tablo 6. KYB karışımları için elde edilen deney ve HAD sonuçları.

\begin{tabular}{ccccc}
\hline & \multicolumn{2}{c}{ Deney } & \multicolumn{2}{c}{ HAD } \\
\cline { 2 - 5 } Kod & $\begin{array}{c}\mathrm{V} \\
\text { Hunisi } \\
\text { (sn) }\end{array}$ & $\begin{array}{c}\text { Geçiş } \\
(\mathrm{PL})\end{array}$ & $\begin{array}{c}\mathrm{V} \\
\text { Hunisi } \\
\text { (sn) }\end{array}$ & $\begin{array}{c}\text { Geçiş } \\
\text { (PL) }\end{array}$ \\
\hline K1 & 20 & 0.93 & 20.2 & 0.88 \\
K4 & 11 & 0.92 & 10.6 & 0.94 \\
K6 & 6 & 0.99 & 7.1 & 0.96 \\
\hline
\end{tabular}

\section{Tartıșma ve Sonuç}

Çalışmanın sonucunda doğruluğu ve hassasiyeti test edilen Hesaplamalı Akışkanlar Dinamiği (HAD) metodu kullanılarak gerçek boyutlardaki geometrilerde KYB uygulamalarının sayısal benzetimi yapılmıștır. Her ne kadar KYB karışımları homojen akışkanlar olarak analiz edilse de HAD benzetimlerinin deneysel sonuçlarla uyumlu olması, bu tür KYB uygulamalarında kullanılabilecek farklı geometri ve karışımlar için ön 
analiz aşamasında risklerin rapor edilebilmesini sağlayabilecek, bu riskleri azaltabilmek için KYB karışımının reolojik parametreleri belirlenmesine yardımcı olabilecektir.

Modelin ileri boyutunda sisteme parçacık taşınım modeli eklenerek doğrudan agrega etkilerinin HAD modelinde yansıtılabileceği düşünülmekte olup ileri çalıșmalarda bu noktaya odaklanılacaktır.

\section{Teşekkür}

Bu çalışma TÜBİTAK 3001- Başlangıç Ar-Ge Projeleri Destekleme Programı kapsamında yürütülen 215M069'nolu proje ile hazırlanmış olup yazarlar TÜBİTAK'a finansal desteğinden, BASF firmasina malzeme desteklerinden ve ayrıca Enes OĞUZ ve Ayberk KARAASLAN'a deneylerdeki katkılarından dolayı teşekkürlerini sunar.

\section{Kaynakça}

[1] Baradan, B., Felekoğlu, B. 2004. Kendiliğinden Yerleşen Betonların Mekanik Özellikleri. Beton 2004 Kongresi, İzmir, 234-243.

[2] Şahmaran, M., Yaman, İ.Ö. and Tokyay, M. 2009. Transport and Mechanical Properties of Self Consolidating Concrete with High Volume Fly Ash. Cement and Concrete Composites, 31, 99-106.

[3] Corradi, M., Khurana, R., Magarotto, R. and Torresan, I. 2002. Zero Energy System: An Innovative Approach for Rationalized Precast Concrete Production. BIBM 17th International Congress of the Precast Concrete Industry, Istanbul, Turkey.
[4] Tohumcu, İ. ve Bingöl, A.F. 2013. Silis Dumanı ve Uçucu Kül Katkılı Kendiliğinden Yerleșen Betonların Taze Beton Özellikleri ve Basınç Dayanımları. DEÜ Mühendislik Fakültesi Mühendislik Bilimleri Dergisi, $15,31-44$.

[5] Skarendahl, A. and Petersson, 0 . 2000. Self Compacting Concrete. State-of the- art Report of RILEM Technical Committee 174 - SCC, RILEM Publications, Chachan, Cedex, France, 17-22.

[6] EFNARC, 2005. Specifications and Guidelines for Self Compacting Concrete. (2005).

[7] Qi, B.H., Fu, Z.J., Yan, S. and Liu, F.X., 2012. Numerical Simulation on Concrete Pouring Process of Self-Compacting Concrete-Filled Steel Tube. 15 WCEE, Lisboa, 18.

[8] Kulasegaram, S., Karihaloo, B. L. and Ghanbari A. 2011. Modelling the Flow of Self-Compacting Concrete. International Journal for Numerical and Analytical Methods in Ggeomechanics, 35, 713-723.

[9] Georgiadis A.S., Fytanidis D.K., Anagnostopoulos N.S., 2010. Simulating Self-Compacting Concrete Fluidity Tests Using Computational Fluid Dynamics Techniques: Approaches and Challenges. 4th International Conference from Scientific Computing to Computational Engineering, Athens, Greece, 1-8.

[10] Deeb, R., Kulasegaram, S. and Karihaloo, B.L., 2014. 3d Modelling of the Flow of SelfCompacting Concrete with or without Steel Fibres Part I: Slump Flow Test, Part II: L-Box Test and The Assessment of 
Fibre Reorientation During the Flow. Computitional Particle Mechanics, 1 (4), 373-408.

[11] Kurokawa, Y., Tanigawa, Y., Mori, H., and Nishinosono, Y.: Analytical Study on Effect of Volume Fraction of Coarse Agregate on Bingham's Constants of Fresh Concrete, Trans. of the Japan Concrete Institute, Vol. 18, 1996, 37-44

[12] Thrane, L.N., Szabo, P., Geiker, M., Glavind, M., Stang, H.: Simulation of the test Mehtod "LBox" for Self-Compacting Concrete, Annual Trans. of the Nordic Rheology Society, vol. 12, 2004, Reykjavik, Iceland, 47-54

[13] Gram, A. and Silfwerbrand, J. 2011. Numerical Simulation of Fresh SCC Flow: Applications. Materials and Structures, 44, 805-813.

[14] Gram, A. 2009. Numerical Modelling of Self-Compacting Concrete Flow - Discrete and Continuous Approach. "Royal Institute of Technology (KTH), Department of Civil and Architectural Engineering Division of Structural Design and Bridges, TRITA-BKN. Bulletin 99,Stockholm, Sweden, (99),1103-4270.

[15] TS 706 EN 12620. 2003. Beton Agregaları. Türk Standartları Enstitüsü, Ankara.

[16] TS EN 12350-9. 2011. BetonTaze Beton Deneyleri-Bölüm 9: Kendiliğinden Yerleşen BetonÇökme-V Hunisi Deneyi. Türk Standartları Enstitüsü, Ankara.

[17] TS EN 12350-10. 2011. BetonTaze Beton Deneyleri-Bölüm 10: Kendiliğinden Yerleşen Beton-L
Kutusu Deneyi. Türk Standartları Enstitüsü, Ankara.

[18] Aggarwal, P., Siddique, R., Aggarwal, Y. and Gupta, S.M. 2008. Self Compacting ConcreteProcedure for Mix Design", Leonardo Electronic Journal of Practices and Technologies, 12, 15-24.

[19] Zeng, S., Shi, J. and Guo, W. 2015. Back Analysis of SelfCompacting Concrete Rheological Parameters Based on $\mathrm{H}-\mathrm{B}$ Model. International Conference on Architectural, Civil Engineering, Guangzhou, China, 183-188. 